\title{
Combatting Against Covid-19 \& Misinformation: A Systematic Review
}

\author{
Sana Ali $^{1}$ (D) \\ Received: 20 July 2020 / Revised: 10 August 2020 / Accepted: 27 August 2020/ \\ Published online: 7 October 2020 \\ (c) Springer Nature Switzerland AG 2020
}

\begin{abstract}
Accompanied by false information, mass media content is hindering efforts to cope with the current outbreak. Although the World Health Organization and other concerned bodies are notified regarding misinformation, myths and rumors are highly prevalent. This paper aims to highlight the misinformation and its potential impacts during the Covid-19 by using the Systematic Review Approach. The researcher randomly selected $n=35$ research articles published from 2015 to 2020, witnessing the misinformation as a major concern during previous endemics and the current Covid-19 pandemic. Myths and rumors through traditional and new media platforms cause Xenophobia, LGBT Rights violations, and psychological disorders among the masses. Despite the efforts made by the World Health Organization, much more is required to nullify the impacts of misinformation and Covid19. Therefore, the researcher recommended improved global healthcare policies and strategies to counteract against misinformation to mitigate the impacts of Covid-19.
\end{abstract}

Keywords Healthcare $\cdot$ Covid-19 $\cdot$ Pandemic $\cdot$ Misinformation $\cdot$ Mass media $\cdot$ Social media

\section{Introduction}

Corona Virus is a threatening respiratory disease that has been described more than fifty years ago, causing various diseases in animals, including gastroenteritis, damaging the central nervous system, and respiratory system (Weiss and Navas-Martin 2005). However, it is only linked with damaging the respiratory system leading to death (van der Hoek 2007). One of the most prominent outbreaks of Severe Acute Respiratory Syndrome (SARS) can be traced back in 2003 with an ecological origin in bats and affirmed that the virus does not have any laboratory origins (WHO 2020), while Middle East Respiratory Syndrome (MERS-CoV), also raised as one of the most acute respiratory diseases (World Health Organization 2014). Many studies also found that these viruses affect the animals and transmit to humans, for instance, SARS-CoV-1 first infected the cats and then transmitted to humans. Likewise, Middle East Respiratory Syndrome (MERS-CoV) was found in camels

Sana Ali

sana_leo1990@hotmail.com

1 Allama Iqbal Open University, Islamabad, Pakistan 
and transmitted to humans (WHO 2020). The available genetic sequence data showed a close between viruses found in camels also found in humans (World Health Organization 2014). Therefore, on December 31st, 2019, the World Health Organization was formally notified regarding a cluster of pneumonia cases in Wuhan, China. Ten days later, the World Health Organization again informed about 282 confirmed cases in the neighboring countries, including Japan, Thailand, and Korea. Twelve people were in critical condition, 51 were hospitalized due to severe illness, and six were died (Chaplin 2020). During January 2020, a total of 2,798 cases of Corona Virus had been reported worldwide. Besides, several travel-related and isolation cases were reported from the United States, Vietnam, Austria, and Korea. As of January 28th, more than 80 deaths were also confirmed in China (Cortellis 2020). As a result, the World Health Organization declared it a global health emergency and introduced several healthcare protocols to mitigate its potential impacts (Baumeister 2019).

Similarly, the COVID-19 outbreak also raised many social and economic challenges worldwide (J. Wang and Wang 2020). Also, the vaccine is yet not developed, which further worsens the situation (Cortellis 2020) whereas, UNICEF (2020) considers taking all the preventive measures as an only immunization to mitigate the virus transmission. For this purpose, media platforms realized the need to educate the people to bring the positive attitudinal changes as mass media are the essential resources to supply credible information (Zhong et al. 2020) however, combating rumors and myths regarding Corona Virus is a major challenge for media today. For instance, FOX News faced criticism for spreading particular misinformation and false beliefs regarding the pandemic as Hannity and Tucker Carlson Tonight were the two most-watched shows framing the pandemic as a part of President Trump's political agenda (Bursztyn et al. 2020). In this context, there are four main areas where people seek information but are highly accompanied by rumors and false information (Geerdink 2020) (i) transmission and the symptoms of the disease, (ii) cure and prophylactics, (iii) origins and causes (iv) impacts and effectiveness of policies designed by healthcare organizations (Culp 2020). Figure 1 below illustrates the primary sources of infodemic that can make pandemic worse and even more challenging.

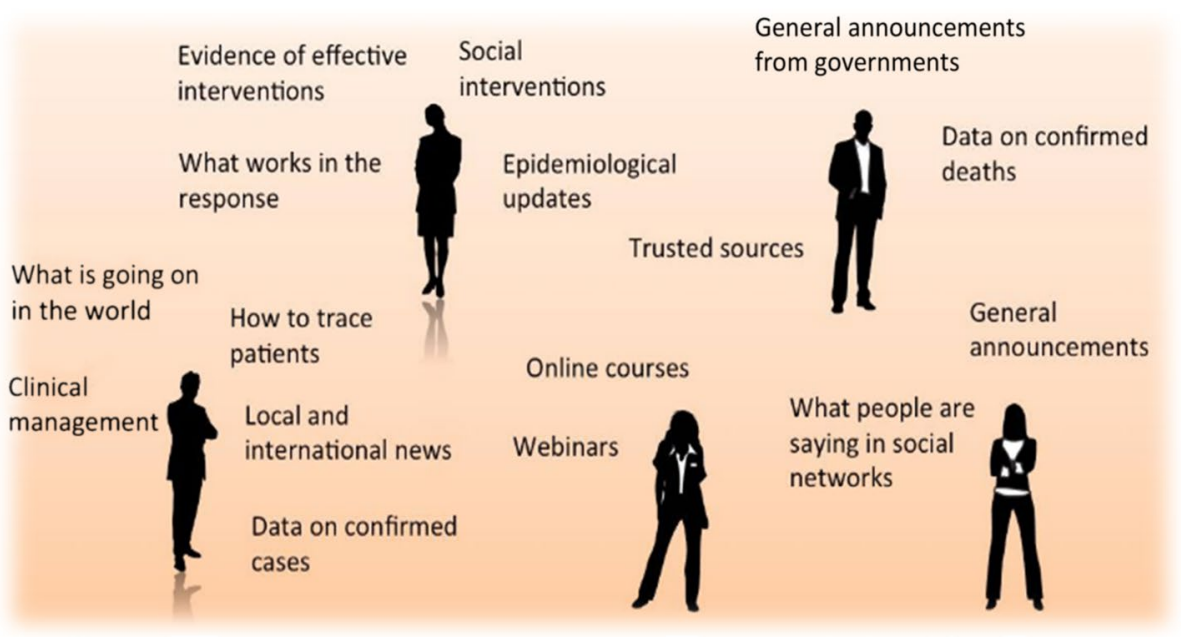

Fig. 1 (Pan American Healthcare Organization, 2020) 
In February 2020, the World Health Organization affirmed the Covid-19 pandemic accompanied by misinformation (WHO 2020). According to Colomina (2020), one of the significant differences between Covid-19 and previous outbreaks is that now fears are immediately viralized to provoke confusion and uncertainty. In this regard, Social Media platforms are mainly disseminating false information along-with traditional media resources. Although increased access to digital media platforms facilitated exponential access to information during the current pandemic, several fabricated stories are shared without quality checking and background (Pan American Healthcare Organization, 2020).

The rapid spread of the Corona Virus during the past couple of months led to several conspiracy theories prevailing through online resources with a common theme that Virus is artificially created according to a particular agenda. This information was disseminated initially from unknown Social Media accounts and engaged more than 20 million people worldwide (Mian and Khan, 2020). As the World Health Organization warned about misinformation due to an independent media usage, today, people are finding it hard to search for a reliable source of information, hindering the response efforts causing severe damage to the struggle for mitigating the outbreak (Article 19 2020). As noted by Bontcheva (2020), both misinformation creates confusion regarding scientific contributions to counteract against Covid-19. Direct transmission adversely affects every individual and society on this planet, causing more harm and destruction during the current outbreak.

Thus, this study supports the existing literature concerning misinformation and its potential impacts, especially during the current Covid-19 pandemic. Review studies are unique as they authenticate the previous studies and provide more ideas for future research on the same topic (Young 2017). Therefore, in the third section, the researcher discussed relevant studies witnessing information and their potential impacts. In the fourth section, the researcher discussed the steps are taken up by the World Health Organization, United Nations, and other concerned bodies to mitigate the misinformation and further made the conclusions. Finally, in the last section, study, contributions and limitations are mentioned along-with the relevant recommendations.

\section{Literature Review}

\section{Healthcare Misinformation \& Media}

Recent trends in mass media ecosystems raise critical concerns regarding misinformation and audience susceptibility to contain it. As compared to past, misinformation is more capable of rapid dissemination due to audience-centered Social Media platforms. Along with traditional media channels, online platforms are a subtle source of misinformation that further worsen the situation (Lazer et al. 2017). However, misinformation is not the result of sub-standard media practices, instead, it results from poor media practices. Nevertheless, poor practices misinformation leak into real news media practices, and for this reason, today, media resources are confronting the risk of "being drowned by cacophony" (Ireton and Posetti 2018). In this regard, Wojczewski et al. (2015) examined the portrayals of local healthcare crises and healthcare services in Ugandan newspapers. The researchers utilized the qualitative approach and selected two popular newspapers in Uganda. Results revealed that although newspapers published several news reports during the designated period, they attributed the healthcare issues to weak government, corruption, and lack of attention towards the healthcare management system. Therefore, the researchers concluded that 
the reports were narrowly targeting political entities and less concerned about the health wellbeing. Gollust et al. (2019) further addressed misinformation in televisions as a result of agenda-setting and causing severe threats to local healthcare systems and undermining ongoing health-wellbeing efforts. The researchers cited the example of cancer-based news reports on the US news media channels and highlighted how most of the news and programs were based on cancer, neglecting other diseases, including HIV. This excessive exposure to the single health issue also contained rumors, myths, and false information about cancer, diagnosis, and treatment in the past. Also affirmed by Ophir (2019), as he investigated the American newspapers' coverage of three famous endemics in the past, including Zika, H1N1, and Ebola. The researchers used content analysis and interview techniques and selected a sample of $n=5,006$ articles from the local newspapers. Findings showed that the relevant news articles mainly contained framed information, capable of spreading misinformation. After exposure to selected news articles, respondents also revealed an increased uncertainty towards the Crisis and Emergency Risk Communication (CERC) and the Centers for Disease Control and Prevention (CDC).

However, critics especially describe the current period as an "era of false information" spread through digital media resources. All the media types facilitate this dissemination but new media platforms are comparatively more productive resources (Y. Wang et al. 2019). The researchers also analyzed the relevant literature witnessing false information on digital media platforms. The researchers selected a sample of $n=57$ research articles and found that misinformation could be easily found during the healthcare crisis, especially Ebola and Zika viruses. Similarly, misinformation was also reported concerning cancer, HIV, and others.

Similarly, Swire-Thompson and Lazer (2020) scrutinized the correlation between misinformation and online available healthcare mobile applications and Social Media posts. According to the researchers, during past online health misinformation, for instance, Measles, Mumps, and Rubella vaccination cause Autism among children. The systematic review of the literature also validated that digital platforms are the richest sources of misinformation. Likewise, misinformation is only characterized as an organized effort to avail power, personal interest, and control over the belief system. Another study to examine the misinformation through Social Media was conducted by Ghenai and Mejova (2018). The researchers selected a sample of $n=4,212$ to obtain discussions about cancer, its diagnosis, and treatment. Results indicated that the rumors about cancer treatment were the main topic of discussion, containing many retweets. Bold claims about different drinks and foods i.e., ginger, banana, honey, and others, were the most circulated myths about the treatment. Therefore, with the value of $0.000^{* * *}(p \leq 0.005)$, the researchers found a strong significant correlation between digital media and misinformation.

\section{Misinformation \& Covid-19}

The right to freedom of information and expression is absolute; sometimes, it is accompanied by propaganda and misinformation. An explicit example can be seen during the Covid-19 pandemic, where different media platforms are found disseminating the myths and false information (Article 19 2020). For this purpose, Hall Jamieson and Albarracín (2020) examined the United States electronic news media coverage regarding misinformation. Probability-based surveys during the beginning of Covid-19 revealed that news reports on NBC news broadcasted accurate information and reinforced awareness behavior; however, FOX news was mainly found disseminating conspiracy regarding Covid-19. The 
misinformation mainly involved rumors i.e., CDC is exaggerating the pandemic to harm Donald Trump's reputation. However, according to R, D, Waran (2020), besides the disease outbreak, misinformation through different media resources is also a major challenge. For many, Social Media platforms are comparatively more powerful to spread information. To further validate this, the researchers also investigated the extent to which Social Networking Sites are spreading misinformation using a qualitative study approach. The researchers selected purposive sampling techniques, open-ended interviews, and systematic study methods for data gathering purposes. Results revealed that respondents expressed Social Networking Sites as containing both information and misinformation; however, due to lack of knowledge containing reliable resources, people mostly expose to unauthentic information. Misinformation not only leads them to gather misinformation but also share with others through online platforms. Similarly, Brennen et al. (2020) examined the sources of misinformation regarding Covid-19 in Great Britain. The researchers randomly selected Social Media platforms and traditional media resources. Findings revealed that out of three prominent (YouTube, Facebook, Twitter) Social Media platforms, Twitter contains comparatively highest (59\%) number of misinformation. Likewise, television, compared to print media, spread more misinformation, reinforcing public engagement to disseminate false information through interpersonal communication. Another study to authenticate this phenomenon was conducted by (Kouzy et al. 2020). The researches randomly selected $n=14$ most trending hashtags on Twitter and analyzed $n=673$ Tweets from individual users. Results showed that total $n=153$ Tweets contained myths and $31 \%$ of information was also from unverified accounts, out of which $12 \%$ of accounts misinformation and decontextualized details. Pulido et al. (2020) also investigated the role of online platforms, particularly Twitter, to spread misinformation during the Covid-19. The researchers used the content analysis approach and selected a random sample of $n=1000$ Tweets. Findings showed that a majority of Tweets contained false information (92.0\%), but only $63.3 \%$ misinformation was retweeted. According to the researchers, these $63.3 \%$ Tweets can still be very detrimental for the efforts concerning mitigation of Covid-19.

During the current pandemic, online platforms are easily accessible, easy to use, and are preferred mainly due to substantial public involvement. Accompanied by a lack of objective information, these platforms are a significant source of misinformation and unauthentic news (Accessnow.org 2020). In this regard, Li et al. (2020) scrutinize the role of YouTube videos for disseminating the misinformation during Covid-19. The researchers randomly selected a sample of $n=145$ online videos and used the content analysis technique. Results revealed that the majority (64\%) of online videos mostly contained misinformation i.e., myths, vaccination discovery, and decontextualization. Therefore, more than one-quarter of the most-viewed YouTube videos contained misinformation, and the sources were popular news platforms. ASPI (2020) also investigated the Chinese state media and diplomatic Twitter accounts and types of information spread through them. The researchers selected a random sample of Tweets during March 2020 and found that much of the misinformation was firmly related to conspiracy theories concerning disease origins and the vaccination.

Moreover, $n=65$ of the Twitter accounts were also from unauthentic resources containing retweets of trolls and myths. Therefore, the number of misinformation and retweets were comparatively higher than accurate information and their spread by ordinary users. Likewise, Sharma et al. (2020) designed a track board to identify misinformation through different Twitter accounts. The researchers gathered streaming data from March 1st, 2020 to May, 12th 2020, and found a massive number of Tweets containing discussions on Covid-19. Results gathered from 30.80 million Tweens revealed that the majority of Tweets were themed on four primary topics: Political bias, reliability, conspiracy, and clickbait. 
Although the number of misinformation varied from country to country, the retweeting behavior was a primary mechanism of spreading misinformation.

Furthermore, Laato et al. (2020) examined the extent to which online platforms are spreading misinformation during the Covid-19 pandemic, and what are the potential reasons behind it? The researcher used a structured survey questionnaire and gathered responses from $n=294$ respondents in Bangladesh. Respondents revealed that they receive and share the information without any authentication and filtration. Although they know that information comes from unknown resources, they still share it as online information sharing is a typical behavior today. The researchers concluded that this information sharing behavior is the leading cause of misinformation that may bring adverse outcomes. Pennycook et al. (2020) also analyzed the online information-sharing behavior during Covid-19 among Americans. The researchers selected a sample of $n=1600$ participants and gathered data by using close-ended survey questionnaires. The results indicated that the majority of the respondents prefer to share information without validation. For them, information sharing is essential to aware the masses. However, affirmation is not considerable. On the other hand, a few respondents with critical thinking revealed that they are considerate about information sharing and do not pass on any posts without authentication.

\section{Impacts of Misinformation during Covid-19}

\section{Xenophobia}

Mass media provide individual narratives to a different phenomenon, including biomedical research. Narrative communication deeply affects public perception, especially during the healthcare crises (Caulfield et al. 2019). Riddled with decontextualization, pseudoscience, fake news and rumors, many consider Covid-19 as a result of intentionality and the personal interests as the falsity is not an only problem, but also rumors are spread by highly influential individuals even accompanied by hate speech and racism as well (Geerdink 2020; Colomina 2020). These rumors are strongly associated with the stigmatization of immigrants and discrimination against them. The Covid-19 pandemic's politicization is adopted by several anti-immigrant and hate groups spreading various conspiracy theories claiming the spread of Corona Virus as a result of migration (IIOM 2020). With thousands of new cases every day, Corona Virus causes unprecedented disruption in human societies. Due to the broader spread of misinformation, our understanding of Covid-19 is still evolving. Undermining all the efforts made by health experts worldwide, this misinformation is characterized by adverse outcomes, including intolerance, racism, inequality, and unhealthy behaviors (Limaye et al. 2020). In this regard, Rzymski and Nowicki (2020) examined whether and to what extent Asian medical students face discrimination in Poland. The researcher conducted a cross-sectional study and randomly selected a sample of $n=85$ students from Poland having Asian origin. Participants revealed that they are facing discrimination and isolation due to their origin. They also have to spend their time in isolation, which is adversely affecting their career development. Similarly, Jeung et al. (2020) analyzed the frequency of Xenophobic news reports in American news media and their impacts on real-life situations from February 2020 to March 2020. The researchers conducted both content analysis and review of relevant literature ( $n=216$ articles) witnessing Xenophobia. Results indicated that the number of discriminatory news reports increased from $n=93$ per day to $n=140$ during March. An average of $n=16$ cases is reported regarding Xenophobia, which means that news reports are highly influential on real-life behavior, 
increasing the Xenophobia among the public. According to Article 19 (2020), misinformation causes anti-foreigner and anti-Chinese sentiments in several parts of the globe. This misinformation can be primarily seen on the Social Media platform. However, traditional media also push highly discriminatory content and business communities posting online platforms signed petitions to ban the Chinese customers. Many conspiracy theories also attributed Corona Virus to Jews, Muslims, Bahai's, and other communities, resulting in discrimination and hate crimes (United Nations 2020). Also, the Xenophobia against Chinese is prevalent among European nations. During the current health crisis, the situation hinders the dialogue between Beijing and Europe, amplifying significant disagreements between these two (AIES 2020). Also affirmed by Reny and Barreto (2020), as they investigated the Americans' perceptions towards Asians, mainly Chinese during Covid-19. The researcher selected a sample of $n=4,311$ American respondents and used close-ended structured questionnaires. Results showed that Xenophobia and anti-Asian attitudes were strongly associated with the Covid-19 misinformation. Initially, the anti-Asian attitude was low but highly increased due to a variety of myths, rumors, and decontextualization of news reports.

\section{LGBT Healthcare Rights Violation}

Similarly, the World Health Organization also declared Lesbian, gay, bisexual, trans, and intersex (LGBTI) communities more vulnerable during the current pandemic. Due to the stigmatization and discrimination against LGBTI, several individuals face difficulty accessing healthcare services. They face online hate speech and bullying at home due to the lockdown situation, hindering their fundamental human rights (UNHR 2020). According to GMHC (2020), even old age LGBT individuals living in congregate facilities may also face deprivation of medical; services. Healthcare professionals can refuse their treatment and consider them as potential careers Covid-19 (unconscious bias). Also, among many public healthcare systems, the LGBT community lacks sex and marital status, making them ineligible for the provision of healthcare services (Lokot and Avakyan 2020).

\section{Psychological Distress}

Jayaseelan et al. (2020) investigated the impacts of Social Media based misinformation on audience behavior during Covid19. The researcher used a qualitative approach and selected a sample of $n=13$ undergraduate university-level students. Findings showed that students consider Social Media as a source of information, and most of them like to share the information with others without authentication. However, misinformation covers a significant part of these posts affecting their healthcare behavior and raises uncertainty regarding the local healthcare system. Furthermore, false information about Covid-19 is not a new phenomenon as many academics, researchers, journalists, and policymakers approached World Health Organization and emphasized that this would cause serious risk to public mental and physical health (Brennen et al. 2020). People living in isolation, risk of infectious disease, and quarantine rely mainly on media for information that is more vulnerable to psychological disorders. Curiosity and fear lead them to seek information through different media platforms. In this regard, misinformation plays a vital role in undermining one's mental health by inducing fear, anxiety, and stress. Misinformation also caused food insecurities among the masses with low socio-economic status, intensively exacerbated demand-supply gaps, and largely disrupted supply chain worldwide (Tasnim et al. 
2020). In this regard, Ravi Philip Rajkumar (2020) investigated the impacts of Covid-19 and myths on individuals' mental health. The researcher conducted a thematic review study and found that Anxiety, Stress, and Depression are the most prominent psychological problems during Covid-19. Also, these disorders were strongly associated with disturbed sleep among the public. Therefore, the researcher suggested avoiding syndromal mental health concerns raised by Covid-19 should be eliminated by counteracting against the misinformation and its potential resources. Also affirmed by Tasnim et al. (2020) as they highlighted the misinformation as an increased challenge during global healthcare emergency. Misinformation mainly contains hoaxes, decontextualization, and myths about the origin and etiology of the disease-causing mental disorders among the public. The spread of misinformation is also undermining healthy behaviors and efforts to spread healthcare awareness among the masses. Figure 2 below provides a graphical representation of misinformation sources, types, and potential impacts.

\section{Methodology}

Literature review studies tend to highlight existing concerns with valid argumentation. It is more like finding pieces of a puzzle which further highlights the importance of the relevant phenomenon (Library 2017). In this regard, the current study also utilized a Systematic Review Approach to retrieve suitable research investigations (Habes et al. 2020). The researchers systematically gathered peer-reviewed published research articles from 2015 to June 2020. These articles contained diverse study methods (survey, content analysis, interview, literature review \& others) and paradigm models (quantitative, qualitative) to identify the widespread misinformation and its impacts.

Moreover, the researcher mainly gathered articles from the top 17 journals of media, social sciences, psychology, medicine, health, humanities, and human rights from the 2018 ISI Web of Knowledge Journal Citation Reports according to the value of their impact factor, Scopus and Web of Science indexation. The selected journals involved: International Journal of Biological Science, Educational Research and Reviews, Social

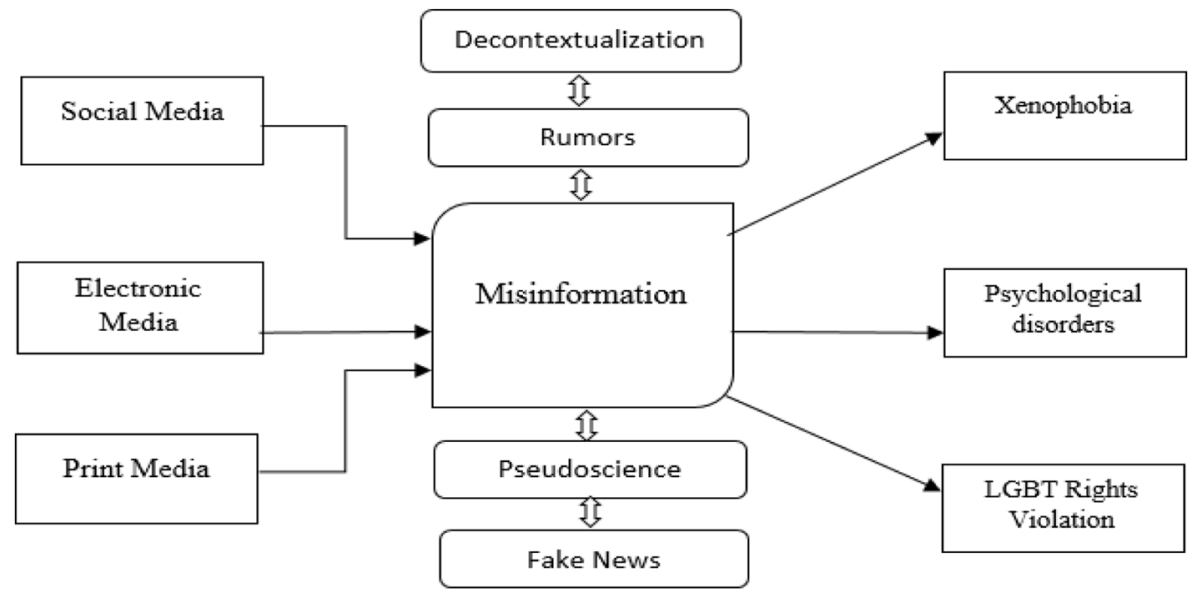

Fig. 2 Source: This Study 
Science and Medicine, Health Communication, Annual Review of Public Health, and others. However, many of the citations also belong to situation reports, perspectives, policy briefs public by the World Health Organisation, International Labour Organization (ILO), and others. Therefore, a total of $n=35$ of the published research content was reported according to the designated criteria. The data of each criterion is given below with the relevant tables and graph:

Figure 3 above shows the percentage of relevant articles by year. However, it is observable that out of $n=35$ research articles, the majority of misinformation related papers published in 2020 during the peak of the Covid-19 pandemic. Besides the healthcare challenges, misinformation also created chaos creating even more severe challenges (Nguyen and Nguyen 2020).

Table 1 above shows the study design of the cited articles. The studies involve experimental design, case study, review approach, and others. However, $n=8$ or $23 \%$ cited articles involve policy briefs and situational reports issued by the World Health Organization, UNESCO, Pan American Health Organization (PAHO), UNICEF, and International Labour Organization (ILO). Similarly, according to the paradigm models, it is observable that a majority $n=13$ or $37 \%$ of studies were quantitative, $n=6$ or $17 \%$ were qualitative, and $46 \%$ of articles were research essays, commentaries, perspectives, policy briefs and, situational reports.

Table 2 above shows the different types of data collection methods in the selected literature. The majority of studies $(n=9$ or $26 \%)$ utilized the media content analysis technique to investigate the potential types and sources of information. However, $31 \%$ of the articles contained policy briefs, situational reports, research perspectives, and others. Likewise, the selected literature also contained an analysis of diverse types of media types. In this regard, a majority $(n=12,35 \%)$ of studies focused on print media and Social Media to investigate the widespread misinformation. According to Orso et al. (2020), due to an increased number of information sources, people widely depend on mass media. During the pandemic, this dependence is creating several problems due to the rampant misinformation.

\section{Percentage of Research Articles}

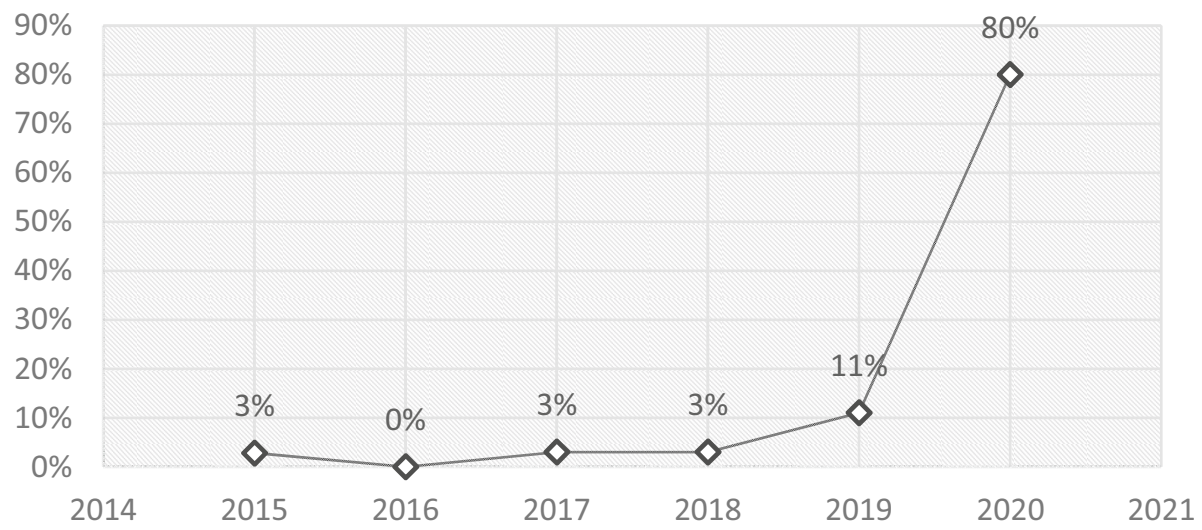

Fig. 3 Percentage of cited research articles according to the publication years 


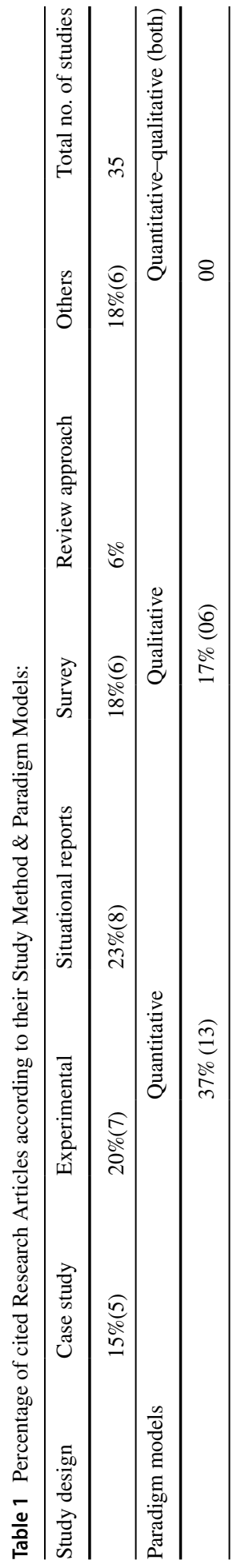


Table 2 Percentage of cited Research Articles according to their Data Collection Method \& Types of Media Resources

\begin{tabular}{llllll}
\hline Data collection methods & Survey & Literature review & Interview & Content analysis & Others \\
\hline & $18 \%(6)$ & $9 \%(3)$ & $3 \%(1)$ & $26 \%(9)$ & $3 \%(1)$ \\
\hline Types of media & Electronic media & Social media & Print media & Others \\
\hline & 03 & 12 & 12 & 18 \\
\hline
\end{tabular}

\section{Discussion \& Conclusion}

Mainstream media platforms mostly contain fake news and rumors. The long-standing issue of misinformation regarding different sociopolitical issues is under constant discussion. However, misinformation during the current pandemic raised many concerns regarding Public health and communication (Ognyanova et al. 2020). $N=35$ studies and reports explicitly witnessed rampant misinformation and its impacts on minorities worldwide (Posetti and Bontcheva 2020). These results are compatible with the World Health Organization (WHO 2020), declaring misinformation as an equally challenging phenomenon (Vicol 2020).

Similarly, most cited studies witnessed Social Media as a primary source of misinformation due to increased online media dependence (Ali 2019). These results are consistent with the study conducted by Brennen et al. (2020), as they found a strong significant correlation between Social Media platforms (Facebook, YouTube \& Twitter) and fake news. Also validated by Pulido, Ruiz-Eugenio, et al. (2020), as they stated that although globalization plays a vital role in spreading healthcare information, Social Networking platforms also contain misinformation. Covid-19 is a dominant part of online discourse, and harmful, personal, and opinionated content adversely affects the current situation. Misinformation is a critical risk for global health and well-being, and during the Covid19 outbreak, people are unable to find any unreliable source of information (Tedros Adhanom Ghebreyesus 2020). Likewise, much of the information we receive from Social Media resources are unreliable (Orso et al. 2020). The situation gets worst when users re-share the news without further confirmation (Mian and Khan 2020). As noted by Islam et al. (2020), Social Media platforms facilitate users to share information of their choice, enjoying the freedom, and represent their opinion. This lack of control over thoughts further amplified radical thinking and claimed to be significant misinformation (Tucker et al. 2018). Conspiracy beliefs raised by misinformation adversely affected the efforts to mitigate the impacts of Covid-19 and minorities worldwide (Barua et al. 2020). The cited literature also witnessed these impacts, mainly resulting in Xenophobia, LGBT rights violation and, several psychological disorders (Ravi Philip Rajkumar 2020; Rzymski and Nowicki 2020; Lokot and Avakyan 2020).

According to international laws, the extraordinary situation requires extraordinary measures that means many fundamental rights, including access to information, freedom to opinion, and freedom to impart the information, restrict the media resources to spread correct information regarding Covid-19 (Accessnow.org 2020). For this purpose, healthcare organizations and individuals are equally obligated to spread correct information and government resources (Toppenberg-Pejcic et al. 2019). To counteract against the impacts of misinformation, it is essential to: 
1 Implement community engagement and national risk communication plan that may include details regarding all the prescribed public health measures.

2 Prioritize two-way communication to gather public feedback and keep them under continuous surveillance.

3 Engage with community based public healthcare networks, i.e., Non-governmental Organizations, media platforms, business sector, education providers, healthcare services, and others.

4 Promote healthcare and hygiene practices by using different communication platforms, consistent with the national healthcare containment recommendations.

However, as both traditional and digital media platforms are accessible today, it is difficult to curb the misinformation. Especially interconnected-ness through new media and mobile technology is identifying the resources, and mitigating the impacts of misinformation are the significant challenges (Sharma et al. 2020). Particularly, misinformation during the current pandemic amplified more significant concerns hindering the global efforts to overcome the outbreak (Pennycook et al. 2020). This multitude of "falsehoods" has even become a matter of life and death. For this purpose, stakeholders and media organizations have the responsibility to spread accurate, objective, and appropriate news as the misinformation hinders global healthcare efforts (USAID 2020). Struggle to overcome the pandemic crucially depends on the public holding appropriate beliefs and attitudes. However, the Novel Corona Virus outbreak is mostly accompanied by false information for the strategic gain on different media platforms, posing a threat to all the ongoing contributions (Bursztyn et al., 2020; ASPI, 2020). For this purpose, besides counteracting against the Covid-19 pandemic, Social Media pandemic also needs attention as both viruses and misinformation spread at the same pace, having the same impacts and challenging the global healthcare scenario today (Depoux et al. 2020).

Therefore, misinformation largely plagued the scientific efforts and communities during the current pandemic. A topic like safety measures, vaccination, disease origins, and others primarily contain myths. For instance, home remedies can cure the Coronavirus. According to most of them, Vitamin-C and garlic intakes are the miracle remedies to treat the disease (Mian and Khan 2020). Similarly, Corona Virus can spread through eyes, Coronavirus is a humanmade virus for personal interests and terrorism, receiving packages and letters from China is not safe, and others (CARPHA 2020). This study also highlighted the widespread misinformation on different media platforms and their impacts.

The world is mostly facing misinformation as Covid-19 significantly amplified the growth and spread of misinformation through different media platforms. Although the role of Social Media is prominent, traditional media platforms are also a source of spreading rumors and false beliefs. Accompanied by hate speech, online bullying, and discrimination, misinformation is a significant challenge during the current pandemic. Counteracting against the misinformation can help to mitigate the impacts of Corvid-19 in the short-term. It will also help us "build back better" by addressing the primary cause of the outbreak by promoting common humanity, solidarity, unity, and inclusion (United Nations 2020). In this regard, accuracy nudges should be the top priority for the media platforms to counter the tide of misinformation during the current pandemic positively. 


\section{Study Contributions}

Depending on the existing literature, this study is capable of increasing our knowledge regarding misinformation during the current pandemic. An extensive number of cited studies are significantly witnessing the rampant misinformation as a significant social challenge. Furthermore, the researcher also proposed a graphical abstract that will support future researchers to examine misinformation and its impacts, especially during the significant healthcare crisis.

\section{Limitations \& Recommendations}

This study does not contain any methodology or primary data, which limits its scope. Similarly, a majority of citations from American investigation is another major limitation. However, the researcher carefully analyzed the gathered data and made the relevant conclusions. Therefore, to further validate this phenomenon, the researcher recommends more studies to investigate the sources of misinformation during the healthcare crisis.

\section{References}

Accessnow.org. (2020). "FIGHTING MISINFORMATION AND DEFENDING FREE EXPRESSION DURING COVID-19 : Fighting Misinformation and Defending Free Expression during COVID-19: Recommendations for States."

AIES. (2020). Covid-19 and Europe-China Relations A Country-Level Analysis.

Ali, Sana. (2019). "Social Media Usage among Teenage Girls in Rawalpindi and Islamabad." Global Media Journal, no. January 2018.

Article 19. (2020). "Viral Lies : Misinformation and the Coronavirus March 2020."

ASPI. (2020). "Covid-19 Disinformation and Social Media Manipulation Trends 8 April-15 April." www. aspi.org.auwww.aspistrategist.org.autwitter:twitter.com/ASPI_ICPC.

Barua, Zapan, Sajib Barua, Salma Aktar, Najma Kabir, and Mingze Li. (2020). "Effects of Misinformation on COVID-19 Individual Responses and Recommendations for Resilience of Disastrous Consequences of Misinformation." Progress in Disaster Science, no. xxxx: 100119. https://doi.org/10.1016/j.pdisa s.2020.100119.

Baumeister, H. (2019). Novel Corona Virus. Indo American Journal of Pharmaceutical Sciences, $23(3), 6$. https://doi.org/10.5281/zenodo.1477753

Bontcheva, Kalina. (2020). "Deciphering COVID-19 Disinformation,” 1-17.

Brennen, Authors J Scott, Felix M Simon, Philip N Howard, and Rasmus Kleis Nielsen. (2020). "Types , Sources , and Claims of COVID-19 Misinformation." Oxford University Press, no. April: 1-13.

Bursztyn, L., Rao, A., Roth, C., \& Yanagizawa-Drott, D. (2020). Misinformation During a Pandemic. SSRN Electronic Journal. https://doi.org/10.2139/ssrn.3580487

CARPHA. (2020). "Debunking the Myths About Alternatives."

Caulfield, Timothy, Alessandro R. Marcon, Blake Murdoch, Jasmine M. Brown, and Sarah Tinker Perrault Jonathan Jerry. (2019). "Health Misinformation and the Power of Narrative Messaging in the Public Spher.” file:///C:/Users/User/Downloads/fvm939e.pdf.

Chaplin, S. (2020). "COVID-19 : A Brief History and Treatments in Development." no May: 23-28. https:// doi.org/10.1002/psb.1843

Colomina, Carme. (2020). "Coronavirus Infodemics and Fake News,” no. March: 1-3.

Cortellis. (2020). "Disease Briefing: Coronaviruses," 1-81.

Culp, W. C. (2020). Coronavirus Disease 2019. A \& A Practice, 14(6), e01218. https://doi.org/10.1213/ xaa.0000000000001218

Depoux, Anneliese, Sam Martin, Emilie Karafillakis, Raman Preet Bsd, Annelies Wilder-Smith, and Heidi Larson. (2020). "The Pandemic of Social Media Panic Travels Faster than the COVID-19 Outbreak." Journal of Travel Medicine, no. March: 1-2. https://doi.org/10.1093/jtm/taaa031.

Geerdink, F. (2020). "Press Freedom and Censorship," 1-18. 
Ghenai, A., \& Yelena, M. (2018). "Fake Cures: User-Centric Modeling of Health Misinformation in Social Media." Proceedings of the ACM on Human-Computer Interaction, 2, (CSCW), 1-2. https:// doi.org/10.1145/3274327

GMHC. (2020). "LGBT Older People \& COVID-19."

Gollust, S. E., Fowler, E. F., \& Niederdeppe, J. (2019). Television News Coverage of Public Health Issues and Implications for Public Health Policy and Practice. Annual Review of Public Health, 40(1), 167-185. https://doi.org/10.1146/annurev-publhealth-040218-044017

Habes, M., Alghizzawi, M., Ali, S., Salihalnaser, A., \& Salloum, S. A. (2020). The Relation among Marketing Ads, via Digital Media and Mitigate (COVID-19) Pandemic in Jordan. International Journal of Advanced Science and Technology, 29(7), 12326-12348.

Hoek, Lia van der. (2007). "Human Coronaviruses : What Do They Cause ?"

IIOM. (2020). "Misinformation, Fake News and the Instrumentalization of the COVID - 19 Pandemic IOM Social Media Campaign in Mexico 20 April 2020."

Ireton, Cherilyn, and and Julie Posetti. (2018). JOURNALISM , 'FAKE NEWS' \& Handbook for Journalism Education and Training.

Islam, A K M Najmul, Samuli Laato, Shamim Talukder, and Erkki Sutinen. (2020). "Since January 2020 Elsevier Has Created a COVID-19 Resource Centre with Free Information in English and Mandarin on the Novel Coronavirus COVID- 19. The COVID-19 Resource Centre Is Hosted on Elsevier Connect, the Company's Public News and Information Website . Elsevier Hereby Grants Permission to Make All Its COVID-19-Related Research That Is Available on the COVID-19 Resource Centre - Including This Research Content - Immediately Available in PubMed Central and Other Publicly Funded Repositories, Such as the WHO COVID Database with Rights for Unrestricted Research Re-Use and Analyses in Any Form or by Any Means with Acknowledgement of the Original Source. These Permissions Are Granted for Free by Elsevier for as Long as the COVID-19 Resource Centre Remains Active. Technological Forecasting \& Social Change Misinformation Sharing and Social Media Fatigue during COVID-19: An a Ff Ordance and Cognitive Load Perspective," no. January.

Jamieson, K. H., \& Albarracín, D. (2020). The Relation between Media Consumption and Misinformation at the Outset of the SARS-CoV-2 Pandemic in the US. The Harvard Kennedy School Misinformation Review, 1, 1-22. https://doi.org/10.37016/mr.2020.012.

Jayaseelan, R., Brindha, D., and Kades waran. (2020). "Social Media Reigned by Information or Misinformation About COVID-19: A Phenomenological Study.” SSRN Electronic Journal, no. AprilMay. https://doi.org/10.2139/ssrn.3596058.

Jeung, Russell, Sarah Gowing, and Kara Takasak. (2020). "NEWS ACCOUNTS OF COVID-19 DISCRIMINATION 2/9-3/7/20."

Kouzy, Ramez, Joseph Abi Jaoude, Afif Kraitem, Molly B El Alam, Basil Karam, Elio Adib, Jabra Zarka, Cindy Traboulsi, Elie Akl, and Khalil Baddour. (2020). "Coronavirus Goes Viral: Quantifying the COVID-19 Misinformation Epidemic on Twitter.” Cureus, 12 (3). https://doi.org/10.7759/ cureus. 7255 .

Laato, Samuli, A. K. M. Najmul Islam, Muhammad Nazrul Islam, and Eoin Whelan. (2020). "Why Do People Share Misinformation during the COVID-19 Pandemic?," 1-20. http://arxiv.org/abs/2004.09600.

Lazer, David, Matthew Baum, Nir Grinberg, Lisa Friedland, Kenneth Joseph, Will Hobbs, Carolina Mattsson, et al. (2017). "David Lazer (Northeastern)." Filippo Menczer, no. May.

Li, H.-Y., Bailey, A., Huynh, D., \& Chan, J. (2020). YouTube as a Source of Information on COVID-19: A Pandemic of Misinformation? BMJ Global Health, 5(5), e002604. https://doi.org/10.1136/bmjgh $-2020-002604$

Library, Western Sydney University. (2017). "Literature Review Purpose.” Western Sydney University Library, no. July: 1-2. https://www.westernsydney.edu.au/_data/assets/pdf_file/0006/1254786/ Literature_review_purpose.pdf.

Limaye, R. J., Sauer, M., Ali, J., Bernstein, J., Wahl, B., Barnhill, A., \& Labrique, A. (2020). Building Trust While Influencing Online COVID-19 Content in the Social Media World. The Lancet Digital Health, 2(6), e277-e278. https://doi.org/10.1016/S2589-7500(20)30084-4

Lokot, M., \& Avakyan, Y. (2020). "Intersectionality as a Lens to the COVID-19 Pandemic: Implications for Sexual and Reproductive Health in Development and Humanitarian Contexts." Sexual and Reproductive Health Matters, 1-5. https://doi.org/10.1080/26410397.2020.1764748.

Mian, A., \& Khan, S. (2020). Coronavirus: The Spread of Misinformation. BMC Medicine, 18(1), 18-19. https://doi.org/10.1186/s12916-020-01556-3

Nguyen, H., \& Nguyen, A. (2020). Covid-19 misinformation and the social (media) amplification of risk: A Vietnamese. Perspective Media and Communication, 8(2), 444-447. https://doi.org/10.17645/ mac.v8i2.3227. 
Ognyanova, K., Lazer, D., Robertson, R. E., \& Wilson, C. (2020). Misinformation in action: fake news exposure is linked to lower trust in media higher trust in government when your side is in Power. Harvard Kennedy School Misinformation Review, 1(4), 1-19. https://doi.org/10.37016/ mr.2020.024.

Ophir, Yotam. (2019). "Spreading News: The Coverage of Epidemics by American Newspapers and Its Effects on Audiences - a Crisis Communication Approach" 80. http://www.redi-bw.de/db/ebsco .php/search.ebscohost.com/login.aspx\%3Fdirect\%3Dtrue\%26db\%3Dpsyh\%26AN\%3D2018-58618 $-141 \% 26$ site $\% 3$ Dehost-live.

Orso, D., Federici, N., Copetti, R., Vetrugno, L., \& Bove, T. (2020). Infodemic and the Spread of Fake News in the COVID-19-Era. European Journal of Emergency Medicine Publish Ah (April-May). https://doi.org/10.1097/mej.0000000000000713

Pan Amercian Healthcare Organization. (2020). "Understanding the Infodemic and Misinformation in the Fight Against" 395.

Pennycook, G., Jonathon McPhetres, Yunhao Zhang, and David Rand. (2020). "Fighting COVID-19 Misinformation on Social Media: Experimental Evidence for a Scalable Accuracy Nudge Intervention." PsyArXiv [Working Paper], 1-24. https://doi.org/10.31234/OSF.IO/UHBK9.

Posetti, Julie; Bontcheva, Karlina. (2020). "Disinfodemic: Dissecting Responses to COVID-19 Disinformation," 1-17.

Pulido, Cristina M., Laura Ruiz-Eugenio, Gisela Redondo-Sama, and Beatriz Villarejo-Carballido. (2020). "A New Application of Social Impact in Social Media for Overcoming Fake News in Health." International Journal of Environmental Research and Public Health 17 (7). https://doi. org/10.3390/ijerph17072430.

Pulido, C. M., Villarejo-Carballido, B., Redondo-Sama, G., \& Gómez, A. (2020). COVID-19 Infodemic: More Retweets for Science-Based Information on Coronavirus than for False Information. International Sociology. https://doi.org/10.1177/0268580920914755

Ravi Philip Rajkumar. (2020). COVID-19 and Mental Health: A Review of the Existing Literature. Asian Journal of Psychiatry, 52(January), 102066.

Reny, T.T., Barreto, M.A. (2020). "Xenophobia in the Time of Pandemic : Othering, Anti-Asian Attitudes, and COVID-19." Politics, Groups, and Identities 0 (0): 1-24. https://doi.org/10.1080/21565 503.2020.1769693.

Rzymski, P., \& Nowicki, M. (2020). COVID-19-Related Prejudice toward Asian Medical Students: A Consequence of SARS-CoV-2 Fears in Poland. Journal of Infection and Public Health, 13(6), 873876. https://doi.org/10.1016/j.jiph.2020.04.013

Sharma, Karishma, Sungyong Seo, Chuizheng Meng, Sirisha Rambhatla, Aastha Dua, and Yan Liu. (2020). "Coronavirus on Social Media: Analyzing Misinformation in Twitter Conversations" 2019. http://arxiv.org/abs/2003.12309.

Swire-Thompson, B., \& Lazer, D. (2020). Public Health and Online Misinformation: Challenges and Recommendations. Annual Review of Public Health, 41(1), 433-451. https://doi.org/10.1146/annur ev-publhealth-040119-094127

Tasnim, S., Hossain, M-M, Mazumder, H. (2020). "Impact of Rumors or Misinformation on Coronavirus Disease (COVID-19) in Social Media." Journal of Preventive Medicine and Public Health, no. April, 171-174. https://doi.org/10.3961/jpmph.20.094.

Tedros Adhanom Ghebreyesus. (2020). "World Health Organization.” https://www.who.int/dg/.

Toppenberg-Pejcic, D., Noyes, J., Allen, T., Alexander, N., Vanderford, M., \& Gamhewage, G. (2019). Emergency Risk Communication: Lessons Learned from a Rapid Review of Recent Gray Literature on Ebola, Zika, and Yellow Fever. Health Communication, 34(4), 437-455. https://doi. org/10.1080/10410236.2017.1405488

Tucker, Joshua, Andrew Guess, Pablo Barbera, Cristian Vaccari, Alexandra Siegel, Sergey Sanovich, Denis Stukal, and Brendan Nyhan. (2018). "Social Media, Political Polarization, and Political Disinformation: A Review of the Scientific Literature." SSRN Electronic Journal, no. March: 1-95. https://doi.org/10.2139/ssrn.3144139.

UNHR. (2020). "COVID-19 AND THE HUMAN RIGHTS OF LGBTI PEOPLE WHAT IS THE IMPACT OF COVID-19 ON LGBTI PEOPLE ?,” no. April: 7-8.

UNICEF. (2020). "Frequently Asked Questions ( FAQ ) Immunization in the Context of COVID-19 Pandemic," no. April: 1-12.

United Nations. (2020). "United Nations Guidance Note on Addressing and Countering COVID-19 Related Hate Speech."

USAID. (2020). COVERING Covid-19.

Vicol, Dora- Olivia. (2020). "Who Is Most Likely to Believe and to Share Misinformation? FE," no. February: 9. 
Wang, Jia, and Zhifeng Wang. (2020). "Strengths, Weaknesses, Opportunities and Threats (Swot) Analysis of China's Prevention and Control Strategy for the Covid-19 Epidemic.” International Journal of Environmental Research and Public Health 17 (7). https://doi.org/10.3390/ijerph17072235.

Wang, Y., McKee, M., Torbica, A., \& Stuckler, D. (2019). Systematic Literature Review on the Spread of Health-Related Misinformation on Social Media. Social Science and Medicine, 240(September), 112552. https://doi.org/10.1016/j.socscimed.2019.112552

Weiss, S. R., \& Navas-Martin, S. (2005). Coronavirus Pathogenesis and the Emerging Pathogen Severe Acute Respiratory Syndrome Coronavirus. Microbiology and Molecular Biology Reviews, 69(4), 635664. https://doi.org/10.1128/mmbr.69.4.635-664.2005

WHO. (2020). Coronavirus Disease 2019. A \& A Practice, 14(6), e01218. https://doi.org/10.1213/xaa.00000 00000001218

—. (2020). "Novel Coronavirus ( 2019-NCoV )," no. February.

Wojczewski, S., Willcox, M., Mubangizi, V., Hoffmann, K., Peersman, W., Niederkrotenthaler, T., et al. (2015). Portrayal of the Human Resource Crisis and Accountability in Healthcare: A Qualitative Analysis of Ugandan Newspapers. PLoS ONE, 10(4), 1-18. https://doi.org/10.1371/journal.pone.0121766

World Health Organization. (2014). "Middle East Respiratory Syndrome Coronavirus (MERS - CoV) Summary and Literature Update - as of 9 May 2014." WHO - Middle East Respiratory Syndrome Coronavirus (MERS-CoV) Summary and Literature Update-as of 9 May 2014, no. May: 1-8.

Young, M. (2017). Quality of Literature Review and Discussion of Findings in Selected Papers on Integration of ICT in Teaching, Role of Mentors, and Teaching Science through Science, Technology, Engineering, and Mathematics (STEM). Educational Research and Reviews, 12(4), 189-201. https://doi. org/10.5897/err2016.3088

Zhong, B. L., Luo, W., Li, H. M., Zhang, Q. Q., Liu, X. G., Li, W. T., \& Li, Yi. (2020). Knowledge, Attitudes, and Practices towards COVID-19 among Chinese Residents during the Rapid Rise Period of the COVID-19 Outbreak: A Quick Online Cross-Sectional Survey. International Journal of Biological Sciences, 16(10), 1745-1752. https://doi.org/10.7150/ijbs.45221

Publisher's Note Springer Nature remains neutral with regard to jurisdictional claims in published maps and institutional affiliations. 